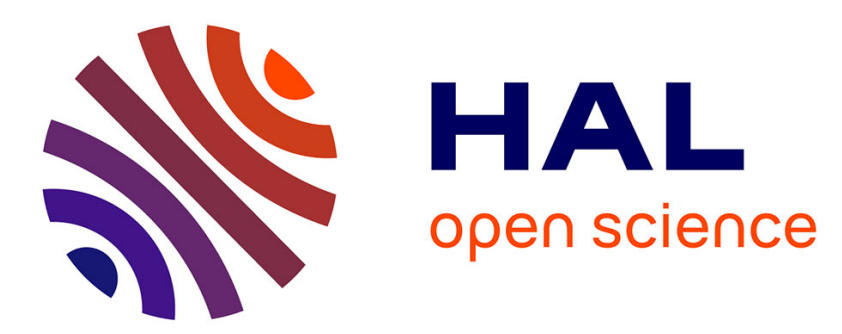

\title{
Assembling Creative Teams in New Product Development Using Creative Team Familiarity
}

Manuel Sosa, F. Marle

\section{To cite this version:}

Manuel Sosa, F. Marle. Assembling Creative Teams in New Product Development Using Creative Team Familiarity. Journal of Mechanical Design, 2013, 135, pp.MD-13-1087. hal-01195557

\section{HAL Id: hal-01195557 \\ https://hal.science/hal-01195557}

Submitted on 10 Sep 2015

HAL is a multi-disciplinary open access archive for the deposit and dissemination of scientific research documents, whether they are published or not. The documents may come from teaching and research institutions in France or abroad, or from public or private research centers.
L'archive ouverte pluridisciplinaire HAL, est destinée au dépôt et à la diffusion de documents scientifiques de niveau recherche, publiés ou non, émanant des établissements d'enseignement et de recherche français ou étrangers, des laboratoires publics ou privés. 


\title{
Assembling Creative Teams in New Product Development Using Creative Team Familiarity
}

\author{
Manuel E. Sosa \\ Associate Professor ofTechnology and Operations Management \\ INSEAD \\ 1 Ayer Rajah Ave, Singapore 138676 \\ manuel.sosa@insead.edu \\ Franck Marle \\ Associate Professor of Project Management \\ Laboratoire Genie Industriel \\ École Centrale Paris, FRANCE \\ franck.marle@ecp.fr
}

\begin{abstract}
Creativity is strongly influenced by the way individuals are organized. One of the most difficult and important challenges when managing innovation is to identify the individuals within an organization who must work closely with each other to maximize the generation of creative ideas. This paper aims to inform managers of new product development (NPD) organizations about forming creative teams. To do so, we extend the notion of team familiarity (i.e., the extent to which team members have worked togetherbefore becoming members of a team) by considering the quality of past interactions. We define creative team familiarity as the degree to which team members have triggered the generation of creative ideas in one another during task-related interactions prior to joining the team. This paper argues that a high level of creative team familiarity (rather thansimply a high level of team familiarity) is positively associated with a team's capability to produceinnovative outcomes. We test this hypothesis in a unique empirical setting involving participants in an international executive MBA program. We also illustrate the implications of our findings by identifying membersin a real NPD organization who would form a creative task force with maximum level of creative team familiarity.
\end{abstract}

Keywords: creative teams; new product development organizations; creativity; team familiarity 


\section{Introduction}

Understanding cognitive and behavioral aspects of the design process is critical to advancingthe research agendain engineering design[1,2].Moreover, because designing new systems is typically a team (rather than an individual) effort [3-6], it is crucial to understand how to assemble successful creativedesign teams [7-9]. Who should be assigned to the next team responsible for generating creative solutions for ...?Questions such as this are commonly faced by innovation managers, who typically address them on an ad hoc basis rather than taking into account how the organization actually works. In addressing this question, this paper unpacks the relationship between team familiarity and the capability of design teams to createinnovativeoutcomes.

Past research has identified, broadly, three types of teams in organizations: tactical, problemsolving, and creative teams [9]. While the first two types focus on executing a well-defined plan and on resolving problems (on an ongoing basis), respectively, creative teams focus on creating something novel and useful. Creative teams are commonly found in any new product development (NPD) organization,structured around NPD projects, such as the ones found in design consultancy firms such as IDEO and Continuum. Such teams typically follow a process characterized by understanding and empathizing with target users, generating many and diverse potential solutions, and prototyping and testing preliminary solutions into a final outcome $[10,11]$. This paper focuses on understanding the role of team familiarity on creative teams' performance.

Team familiarity is the extent to which team members have worked with one another before becoming members of a team [7,12-14]. Previous work has provided conflicting arguments and empirical results concerning the role of team familiarity on team performance. On the positive side, team familiarity is positively related to team performance because it facilitates coordination and cooperation among team members [13]. On the negative side, long-lasting teamsmay limit the diversity of the team's knowledge and experience, which can be detrimental to creative performance[8, 15, 16].

What seems to be missing in this stream of research is a consideration of the quality (rather than the frequency) of past interactionsamong team members. This paperaddresses this limitation by 
introducing the notion of creative team familiarity: the degree to which team members have triggered the generation of creative ideas in one another during task-related interactions before joining the team. We then argue (and empirically test) that what is positively associated with a team's capability to produce innovative outcomes is not high levels of overall team familiarity (based on the existence of past interactions or the lack thereof) but high levels of creative team familiarity. Finding empirical support for such a proposition has implications for the "how to assemble acreative team" decision.

In exploring how product development actors interact to address their task interdependencies, the engineering design literature has used a variety of research methodologies to study the relationship between the communication patterns of developers in the organization and the structure of either the products they develop or the process they use to develop those products [17-21]. Using a simulationbased approach validated in a complex development project carried out at the Jet Propulsion Laboratory, Olson et al. [4] study the interplay between the structure of a complex design problem and the design of the team responsible for solving it in order to develop guidelines for managing task complexity while searching for innovative solutions. A game-theoretical approach [6] models dyadic collaboration of engineers in design projects and finds that common project-related knowledge and diversity of background are important drivers of team performance. More related to the internal functioning of design teams, using an experimental approach $\mathrm{Fu}$ et al. [5] examine how the quality of information inputs received by the team affects their convergence to a solution and the quality of that solution. We contribute to this stream of work by examining how dyadic interactions that have emerged to address past task interdependences can be used to provide important guidelines to managers when they are identifying candidates to assemble creative teams.

The creativity literature has addressed the challenge of organizing for creativity in various ways [22]. Here we use the most widely accepted notion of creativity: the ability to produce something that is both novel and useful[23,24]. The work of Amabile [23] pays particular attention to the role of intrinsic motivation to work on the task as a significant determinant of creativity. As a result, such taskrelatedmotivation is considered to be an important criterion when deciding who should be assigned to a 
creative team [25]. Previous research on creativity has also emphasized the role of knowledge diversity in generating novel and potentially useful ideas [10, 26, 27]. Thus, grouping people with diverse backgrounds and experiences should be an important determinant of a team's creativity [15, 28, 29]. Yet, to realize the benefits of team diversity, teams must also provide a supportive environment amenable to exploration and experimentation $[10,30,31]$. We contribute to this stream of work by looking at how team members' previous creative experiences may be taken into account when forming creative teams.

Our research approach is structured in three steps. First, we formulate a working hypothesis, which predicts that the performance of creative teams is positively associated with the quality of the past interactions of its team members. Second, we test empirically our working hypothesis in a unique empirical setting that involves all members of two classes of an international executive MBA program carrying out a comprehensive design exercise. Third, based on the results of our hypothesis testing, we illustrate (based on data collected in a real organizational setting) how to identifyorganization memberswho would form teams with maximum creative team familiarity.

\section{Hypothesis: Creative Team Familiarity and Creative Outcome}

We start our argument for the use of creative team familiarity as a critical input in assembling design teamsby considering the link between (overall) team familiarity and team performance. As discussed by Huckman et al. [13], there are two reasons to expect a positive relationship between team familiarity and team performance: coordination and cooperation. First, teams with people who have worked together in previous assignments are more likely to coordinate their actions more effectively because they better understand where knowledge resides within the team[12]. Second, team familiarity fosters (among other things) psychological safety and trust, which encourages team members to engage in teamwork[32, 33]. These arguments are in line with simulation-based studies showing a positive relationship between team familiarity and team performance [34]. Empirically, in a study of fluid teams in a large software development firm, Huckman et al. [13]found that the extent to which teams included 
members who worked together on previous projects was positively associated with better team performance (in terms of effort adherence and low-defect products).

Yet, there is evidence suggesting that the relationship between team familiarity and team performance is not trivial. First, the empirical evidence presented by Huckman et al. [13] and Huckman and Staats [14]indicates that the effect of team familiarity is not significantly positive on certain dimensions of performance such as schedule adherence. Because we are focused on creative teams, the key performance dimension of interest is the team's ability to produce creative outcomes. Toward that end, it has been argued that a team that has been together for several engagements is less likely to be creative because the inertia developed in earlier projects is expected to interfere with its creative processes $[8,15,16]$. Hence, assessing team familiarity based solely on the frequency of past interactions does not necessarily predict creative performance.

Second, there is evidence showing that thetype of team familiarity matters: In a follow-up study to Huckman et al.[13] and Huckman and Staats [14], Staats [35]found that "same-location" (instead of "different-location") team familiarity was positively associated with team performance (again on effort adherence and low-defect products).This result suggests that the quality of the past interactions does influence the effect that team familiarity may have on team performance.Given this, we qualify team familiarity by introducing the notion of creative team familiarityas the extent to which past interactions between team members contributed to generate potentially creative ideasin the past[31].

We argue that it is the positive creativity-related experience associated with such prior interactionsthat makes team familiarity an important determinant of a supportive team atmosphere that is conducive to divergent thinking and experimentation[36,37]. When some team membershaveexperienced positive creative interactions prior to joining the team, such familiar team membersare likely to act as creative catalysts again. In that sense, creative team familiarity is expected to foster team trust and motivation to generate and experiment with potentially creative ideas. This argument leads to our main hypothesis. 
Creative team familiarity is positively associated with the team's capability to generate creative outcomes.

\section{Hypothesis Testing}

Testing our hypothesis requiredan empirical setting that fulfilled two important conditions: 1) accessibility to a sizable set of "creative teams"that would perform a controlled design activity and2) the ability to capture the communication patterns among the teams' membersbeforesuch a design activity. We took advantage of the natural setting in an executive master of business administration (EMBA) program to test our hypothesis. This setting was ideal because it provided access to a set of participantswho had a significantly long history of task-related interactions before they were assignedto creative teams. These teams then completed a comprehensive design exercise whose outcome was assessed in an objective manner.Our empirical setting was not a controlled experiment but rather an observational study in which any important confounding factors were controlled for either by randomization during thesetup of the design exercise or by measurementso they could be accounted for during the statistical analysis.

\subsection{Participants}

We gathered data from participants enrolled in an EMBA program offered jointly by Tsinghua University and INSEAD (http://tsinghua.insead.edu.sg/). The program is called TIEMBA; it lasts one and a half years (starting in June and finishing in December) and includes 11 two-week modules with approximately six weeks between them. Modules take place in four different locations: Beijing, China; Singapore; Abu Dhabi, United Arab Emirates; and Fontainebleau, France.Participants in this program have undergraduate degrees in various disciplines and over 10 years (on average) of professional experience. Data gathering took place in the ninth module of the program as part of a compulsorymultidisciplinary course focused on innovation management. Hence, participants had had the opportunity to interact on academic matters for more than 11 months prior to our data collection.

Figure 1 shows, in bold-frame boxes, the four key milestones in the TIEMBA program that were relevant for our data collection: 1) an initial survey to capture communication patterns among participants 
during the first eight modules, 2)the random assignment of participants into design teams, 3)the completion of a comprehensive design exercise, and 4) participation in a product exhibition in which the novelty and functionality of product concepts produced during the design exercise were assessed. These milestones are detailed in the next subsections. Note that because the innovation management course was compulsory, all steps (except the initial survey) required the participation of all students. No additional incentive of any type was offered to the participants. The course grade of each participant was based on a five-page reflection paper in which he or she discussedhow the key lessons of the course would apply tohis or her professional context. The reports were identified by a number instead of the participant's name, so the course grading was blind on the instructor's end.

We replicated the empirical setting shown in Figure 1 for two consecutive TIEMBA classes, graduating in 2010 and 2011. Both classes experienced similar coursework during the first eight modules of the program. In addition, the teaching material for the innovation management course offered to both classes in the ninth module was identical. The only important difference between the two classes was that the 2010 graduating class completed its ninth module in Fontainebleau; the 2011 graduating class did so in Singapore. (We will discuss the implication of running the design exercise in these two different locations below.) Table 1 summarizes the overall characteristics of the two classes.

Because we were interested in testing our hypothesis at the team level ("Are teams with a higher level of creative team familiaritymore likely to producenovel and useful product concepts in the design exercise?"), it was important to have a sufficiently large number of teams to complete any statistical inference. Gathering data from two graduating classes under similar conditions allowed us to test our hypothesis with a sample of 20 teams (eight teams from the 2010 class and 12 teams from the 2011 class). Although we used the pooled sample to complete our statistical analysis, we did control in our analysis for any unobserved difference associated with the two graduating classes. 


\subsection{Initial Survey: Capturing Frequency and Quality of Past Interactions}

The initial survey was designed to capture the communication patterns of the participantsbased on their involvement during academic tasks in the first eight modules. A short presentation was made to all participants at the beginning of the ninth module to introduce the objective of the survey and to emphasize both the research nature of the data collection and its complete disconnection with the grading of any of the program's courses. Each participant was given a sealed envelope containing the survey instrument and was asked to fill it out individually and confidentially. Completing this survey was not compulsory, yet we obtained a 100\% and 90\% response rate from the 2010 and 2011 classes, respectively.

The survey was structured in two sections. The first section included a couple of short questions that could be relevant to the outcome of the design exercise:

- What is your proficiency in French [Chinese]? [Not proficient at all / Just enough to have a short French [Chinese] conversation on the street / Fluent in French[Chinese] $]^{1}$

- Have you worked on new product development before? [Yes / No]

The second section of the survey was a typical social network instrument [38]. The survey displayed a roster of all the participants in the classfollowed by three questions concerning the respondent's past interactions with each classmate. The three questions measured (from the respondent's viewpoint) past dyadic communication frequency, dyadic work-related closeness, and dyadic ease of generating potentially creative ideas.

- Dyadic communication frequency was measured with the following question:Since the TIEMBA program started (and before this Module 9 started), have you worked with [classmate] in any group assignment (either in class or outside classes)? [0 = No; $1=$ Yes, a few times; $2=$ Yes, many times $]$

- Dyadic closeness was measured with the following question (cf.[31,39]):How close is your academic relationship with [classmate]? [ $=$ Very close, this person is among my favorite classmates to work

\footnotetext{
${ }^{1}$ The answer to this question was relevant because the design exercise involved talking to "customers" in a French marketplace in Fontainebleau (for the 2010 class) and a fresh market in Singapore's Chinatown (for the 2011 class).
} 
with; 3 = Close, we enjoy working together in TIEMBA assignments and exercises; $2=$ Less than close; 1 = Distant, we interact only when strictly necessary]

- Dyadic ease of generating potentially creative ideas was measured with the following question (cf.[31,40]):Based on your interactions with [classmate] in TIEMBA assignments or exercises (either in class or outside the classroom), please indicate your level of agreement with the following statement:

"When I interact with this person, it is easy for me to generate NOVEL creative solutions and/or ideas. These novel ideas can be specific to solutions of TIEMBA assignments or to the way we do things (within TIEMBA academic activities)." [7-point scale: Strongly disagree; Disagree; Marginally disagree; Neither agree nor disagree; Marginally agree; Agree; Strongly agree]

Each participant filling out the survey was asked these three questions for each of the other participants on the roster. Although the participants from the same class knew each other because they had been taking classes together in eight modules of the program prior to the design exercise, not every person had worked with every other in class assignments and/or class exercises. Hence, respondents could report "null" past interactions with some of their classmates.Our goal with this survey was to capture the relevant social network data (within participants' corresponding TIEMBA classes) that would help us measure the level of familiarity among the members of the teams that carried out the design exercise.

\subsection{AssemblingDesign Teams}

Each class was split into design teams (eight teams in the 2010 class and 12 teams in the 2011 class). Within each class, teams carried out the design exercise in parallel. The design teams were assembled in a two-step process. First, we randomly assigned one participant who reported being proficient in the local language to each team. This guaranteed that every team had at least one person proficient in the local language. Second, the rest of the participants were randomly assigned to a team. For 
the 2010 class, we formed six teams with four participants and two teams with five participants. For the 2011 class, we formed ten teams with four participants and two teams with five participants.

In both classes, all teams were provided with the same set of materials to build their prototypes, and each team had a dedicated, closed cubicle to complete their design exercise. Most of the interactions during the exercise took place within the team. Interactions external to the team were limited to short interactions with random "customers" in the marketplace and with the instructor (for clarification on the scope of the exercise). Participants did not interact with members of other teams during the design exercise.

The random assignment of participants to teams, plus the fact that all teams were setup in a similar fashion, provided ideal conditions to examine empirically whether (and how) team familiarity would predict any variation observed in the novelty and functionality of the product concepts produced by the teams (above and beyond random variation).

\subsection{Design Exercise}

The design exercise was part of a two-day course on innovation management taught by the first author to all TIEMBA participants during the ninth module of the program. The first day of the course introduced the design process and the basic design principles for addressing the three main challenges of an innovation project: understanding customer needs, generating alternative product concepts, and prototyping and testing final solutions $[11,41]$.

The second day of the course was dedicated to designing an "artifact" to facilitate grocery shopping in a typical French fresh market in the 2010 class and in a typical Singapore Chinatown fresh market in the 2011 class. Specifically, the artifact needed to facilitate the carrying of groceries from a fresh market to home. There were three types of design activities associated with this exercise: 1) assessment of customer needs, which included visiting the fresh market in Fontainebleau or Chinatown; 2) ideation to generate alternative solutions; and 3) building a final prototype of the product concept. All 
teams went through these three phases. Ultimately, each team needed to produce a comprehensive working prototype made primarily out of Tyvek[42].

The specification of this design exercise is fully consistent with the essential features of a "creativity task" defined by the consensual technique for creativity assessment widely used in creativity research. These features specify that a task should ([23], p. 73): “(a) be feasible in the sense that virtually all subjects in the study can produce something that can be assessed by judges, (b) present all subjects with the same set of materials, instructions, and working conditions, (c) allow for considerable flexibility in responses, (d) result in some form of product that can readily be observed by judges, and (e) result in products that can be readily rated by appropriate judges."

The design exercise was setup as a design contest in which teams were asked to balance design features and cost considerations to develop a product concept that would maximize its expected profits in a simulated product exhibition at the end of the exercise. A product concept's expected profit was determined by its expected cost (directly proportional to the weight of the artifact) and its expected revenues (a function of its suggested retail price, which was to be set by the team, and its expected unit sales). To determine the expected unit sales of a given product concept, we assessed its estimated market share (as the fraction of votes it received during the product exhibition) and multiplied it by a given market potential (e.g., 3 million units in Singapore or 20 million units in France). ${ }^{2}$

The design exercise lasted about eight hours. All participants visited their fresh marketplace, and then teams worked in their assigned cubicles to synthesize the identified user needs. Next, teams focused on the generation, evaluation, and selection of product concepts. Before starting this phase, each team received the same set of materials (a roll of Tyvek and a toolkit with basic elements for rapid prototyping and brainstorming).In this phase, all teams were encouraged to make rapid prototypes of their ideas. The

\footnotetext{
${ }^{2}$ Formally, the following expression to estimate expected profits per team was used [42]:

$\mathrm{E}[$ Profit per team $]=$ MarketPotential $\mathrm{x}$ MarketShare $\mathrm{x}[0.70 \mathrm{x}$ UnitRetailPrice - UnitCost $]$. The revenue side of this equation assumes that the team gets $70 \%$ of the retail price (set by the team) for each unit sold while $30 \%$ of the retail price goes to the retailer. To calculate the product's unit cost it is assumed that 1 gram $=1$ cent.
} 
deadline to complete their design was announced at the beginning of the exercise, and all teams were reminded of it throughout. All teams finished their final prototype on time.

At the end of the exercise, final prototypes were weighed so that each team could estimate the unit cost of their product concept. All teams had about 20 minutes to prepare a short presentation of their product concept for the product exhibition in which the final prototypes would be evaluated.Before the product exhibition, each team privately decided the retail price of their product concept and communicated it to the instructor. Each team made public the retail price of their product concept only during their product exhibition.

\subsection{Product Exhibition}

Aproduct exhibition was scheduled at the end of the day to evaluate the final prototypes developed by each team. All teams were given equal opportunity (in terms of time and space) to present their product concepts to their classmates. The order of the presentation was random. After having seen all the product concepts, all members in the audience acted as judges and voted for their top two favorite designs (excluding their own).

The audience was asked to evaluate all product concepts based on their innovative elements and functionality.The voting was done individually and secretly after all product concepts were presented and examined by the audience. Only the instructor saw the individual votes when aggregating them to estimate the "market share" of each product concept.Both at the beginning of the product exhibition and before the audience voted, it was emphasized that class members needed to submit an "honest" vote for what they believed were the two most novel and useful product concepts (excluding their own), not only for ethical reasons but also because an objective independent and individual assessment was required to appropriately assess the quality of the product concepts.

Class members were also reminded that the course grading was independent of the outcome of the product exhibition, so that participants had nosignificant personal incentive to cast an unethical vote.The evaluation and voting werenecessary not only to estimate the market share in our design exercise 
but also to assess the novelty and usefulness of the product concepts created by each team relative to the other teams.It is important to emphasize that all teams were required to use their final prototypes during their two-minute presentations to illustrate the novel and functional aspects of their product concepts. This limited the possibility that teams would try to distort the audience's perception with a non-productrelated "marketing show."

Using peer reviews to evaluate the novelty and appropriateness of product concepts is consistent with the notion of "appropriate judges" used for assessing creative outcomes [23,43]. As mentioned by Amabile ([23], pp. 72-73), "some formal training in the field maybe necessary for judges to even understand the products they are assessing. ...Judges should be closely familiar with the works in the domain at least at the level of those being produced by the subjects." That is, judges should be "familiar enough with the domain to have developed, over a period of time, some implicit criteria for creativity, technical goodness, and so on." In our setting, peers who had been immersed in the same design challenge had the most appropriate training to assess the novelty and usefulness of the product concepts. This is also consistent with Stein's view of a creative product as an artifact that is accepted as useful, tenable, or satisfying by a group of "significant others," defined as "a formally or informally organized group of persons that has the ability and expertise to evaluate developments in its own field" ([43], p. 35). Note that we refrained from usinga product decomposition-based evaluation of the concepts [5] because "novelty" and "overall functionality" (the two dimensions of interest that determine the innovativeness of a product concept) are holistic attributes of the product concepts [41].

\subsection{Measures}

Because our hypothesis relates the creative familiarity of a team with its capability to produce a novel and useful product concept, we must define all our measures at the team level. Our dependent variable captures the overall perceived design quality of the concept produced by a design team. Our key predictor variable measures, in alternative ways, team familiarity. Finally, although our research design controlled

\footnotetext{
${ }^{3}$ Using peers as judges to evaluate the novelty and appropriateness of creations is also common in the academic community when determining the material to be published in journals and conference proceedings.
} 
for many factors that could potentially confound the relationship between team familiarity and the team's capability to innovate (e.g., no interactions across teams, no systematic difference in team resources, similar contextual conditions across teams), we still measurevarious factors that could influence the relationship between the dependent and predictor variables.

\subsubsection{Dependent variable: Perceived product concept design quality}

In line with previous research in creativity, we assess the capability of a design team to produce something novel and useful by having peer colleagues evaluate the product concepts presented in the exhibition[23,43]. We measure the overall design quality of a team's product concept by the adjusted fraction of votes it received at the end of the product exhibition. Because our judges were the members of the other design teams, teams with five members had a slight disadvantage because they were evaluated by fewer peers than the four-people teams. Hence, we assess the overall quality of a product concept as the number of votes received divided by the total number of votes cast by the members of all other teams. Formally,

$$
\text { product_concept_perceived_quality }_{i}=\frac{\text { votes received by product } \text { concept } i}{\text { all votes } \text { in product exhibition }- \text { votes by team } i}
$$

Finally, to test the reliability of our dependent variable, we compared the rankingsof product concepts in the product exhibition of the 2011 class with the rankings generated by aggregating input from a few external guests (members of the staff of the TIEMBA program) attending the product exhibition. Guests were debriefed with the scope of the design exercise at the beginning of the product exhibition and were asked to provide their favorite product concepts based on novelty and functionality. The Spearman correlation between the rankings was positive and significant $(0.631, p<.003)$.

\subsubsection{Predictor variables}

We devisedvariousalternative measures to capture team familiarity as a function of the frequency or the quality of past dyadic interactions between the members of a team. To define our measures we captured the dyadic responses to the initial survey in three matrices for each class: a frequency interaction matrix 
$(\mathbf{F})$, a closeness interaction matrix $(\mathbf{C})$, and a creative interaction matrix $(\mathbf{D})$. Similar to design structure matrices (DSMs) used to capture interdependencies in engineering systems [19,44,45], these interaction matrices are square and capture the frequency, closeness, or dyadic creativity associated with past interactions between the members of the two classes. For instance, cell $f_{j k}$ in matrix $\mathbf{F}$ of class 2010 captures past interaction frequency reported by person $j$ concerning classmate $k$.

First, we devise two measures of team familiarity, defined as the extent to which members of a team had interacted in past task-related assignments[12,14].

$$
\begin{gathered}
\text { overall_team_familiarity }_{i}=\frac{\sum_{j} \sum_{k} \delta_{i j k} f_{j k}^{b}}{N_{i}\left(N_{i}-1\right)} ; j \neq k \\
\text { frequency_team_familiarity }_{i}=\frac{\sum_{j} \sum_{k} \delta_{i j k} f_{j k}}{N_{i}\left(N_{i}-1\right)} ; j \neq k
\end{gathered}
$$

where $f_{j k}=$ the interaction frequency reported by actor $j$ with respect to actor $k ; f_{j k}^{b}=1$ if $f_{j k}>0$.In addition, $\delta_{i j k}=1$ if actors $j$ and $k$ belong to team $i$, and $\delta_{i j k}=0$ otherwise; and $N_{i}$ is the number of members of team $i$ that responded to the survey. ${ }^{4}$

Next, we measure the average dyadic ease of generating creative ideas in the past interactions in a team as follows:

$$
\text { Avg_past_creative_interaction }_{i}=\frac{\sum_{j} \sum_{k} \delta_{i j k} d_{j k}}{\text { Count of past creative interactions in team } i} ; j \neq k
$$

where $d_{j k}=$ the answer (on a seven-point scale) of respondent $j$ to the dyadic creative interaction question with respect to actor $k$.

We then devised a couple of measures of team familiarity to capture the "quality" of past dyadic relationships between the members of a team. First, we estimate closeness team familiarity, which is based on the closeness of the dyadic relationships (based on past academic-related interactions) between the members of a team. Hence,

\footnotetext{
4 Note that in most cases $N_{i}$ equals team size. Otherwise our variables also exclude the input from nonrespondents on the numerator so that the variables remain unbiased.
} 


$$
\text { closeness_team_familiarity }_{i}=\frac{\sum_{j} \sum_{k} \delta_{i} c_{j k}}{N_{i}\left(N_{i}-1\right)} ; j \neq k
$$

where $c_{j k}=$ the reported past dyadic work-related closeness reported by actor $j$ with respect to actor $k$.

Then, we define creative team familiarity (our main predictor variable), as follows:

$$
\text { creative_team_familiarity }_{i}=\frac{\sum_{j} \sum_{k} \delta_{i} d_{j k}}{N_{i}\left(N_{i}-1\right)} ; j \neq k
$$

where $d_{j k}=$ the reported past dyadic creative interaction reported by actor $j$ with respect to actor $k$.

Finally, and as an alternative way to measure the notion of creative team familiarity, we split our overall team familiarity measure into positive, neutral, and negative creative team familiarity by using the values of dyadic creative interactions associated with each past interaction between team members. That is, we define a positive past creative interaction if the respondent "marginally agrees," "agrees," or "strongly agrees" with the statement that measures dyadic ease to generate creative ideas. If the respondent "neither agrees or disagrees" with this statement, then such an interaction is counted as neutral creative interaction. Finally, if the respondent "marginally disagrees," "disagrees," or "strongly disagrees" with this statement, such an interaction is counted as negative creative interaction. Hence,

$$
\begin{aligned}
& \text { positive_creative_team_familiarity } y_{i}=\frac{\sum_{j} \sum_{k} \delta_{i} d_{j k}^{\text {positive }}}{N_{i}\left(N_{i}-1\right)} ; j \neq k \\
& \text { neutral_creative_team_familiarity } y_{i}=\frac{\sum_{j} \sum_{k} \delta_{i} d_{j k}^{\text {neutral }}}{N_{i}\left(N_{i}-1\right)} ; j \neq k \\
& \text { negative_creative_team_familiarity }_{i}=\frac{\sum_{j} \sum_{k} \delta_{i} d_{j k}^{\text {negative }}}{N_{i}\left(N_{i}-1\right)} ; j \neq k
\end{aligned}
$$

where $d_{j k}^{\text {positive }}, d_{j k}^{\text {neutral }}$, and $d_{j k}^{\text {negative }}$ are binary variables indicating whether the past dyadic creative interaction $j k$ is positive, neutral, or negative, respectively. 


\subsubsection{Control variables}

Because this is not a controlled experiment, it is important to control in our analysis for some factors that could affect the relationship between dependent and predictor variables. Hence, we include the following control variables:

- Singapore dummy (singy). This indicator variable is equal to 1 for the 12 teams fromthe 2011 class that was held in Singapore, and 0 otherwise. This variable controls for any unobserved factor associated with running the design exercise in Singapore (for the class of 2011).

- Suggestedprice (price). This variable captures the suggested retail price of each product concept. As with any other product attribute, suggested retail price (a requirement for the class simulation)can influence the assessment of the quality of the product concept.

- Team NPD experience (NPD_experience). This is measured as the fraction of team members who reported (in the first survey) having had experience in new product development (NPD) in the past.

- Team dynamics (team_dynamics). At the end of the design exercise, individuals were asked to fill out a short follow-up survey capturing various dimensions of team dynamics during the design exercise. Responses were completely confidential. In addition, participants were assured that their responses were processed after course grades were submitted, ensuring that responses would not influence their course performance in any way. We use this survey to capture team dynamics, based on respondents' level of agreement with each of the following statements [46].

- My thoughts and comments were respected and considered by my teammates.

- Our team worked well together.

- Each member of our team contributed their fair share to the joint effort.

- Our team was able to make high-quality decisions.

Table 2 presents a summary of dependent, predictor, and control variables plus descriptive statistics and correlations. 


\subsection{Statistical Analysis}

To test our hypothesis, we estimate a regression model of the following form:

product_concept_perceived_quality

$$
=\beta_{0}+\beta_{1} \cdot \operatorname{singy}_{i}+\beta_{2} \cdot \text { price }_{i}+\beta_{3} \cdot \text { experience }_{i}+\beta_{4} \cdot \text { team_dynamics }_{i}+\beta_{5} \cdot \text { team_familiarity }_{i}+\epsilon_{i}
$$

This equation predicts the dependent variable of interest (i.e., the product concept perceived design quality of team $i$ ) as a linear function of four control variables, a predictor variable, an intercept $\left(\beta_{0}\right)$, and an error term $\left(\epsilon_{i}\right)$. To estimate the regression coefficients $\left(\beta_{k}\right)$, we fit the model to our sample of 20 design teams. Of particular interest is coefficient $\beta_{5}$. A positive and significant $\beta_{5}$ would indicate that higher values of the predictor variable included in the modelare associated with higher values of product_concept_perceived_quality.Because we measure the predictor variable (team familiarity) in alternative ways to be able to test our hypothesis, Table 3shows the coefficient estimates of the various regression models used to test our hypothesis with various measures of team familiarity.Note that all the regression models include the four control variables; Table 3 shows the estimates $\beta_{1}-\beta_{4}$ across the seven regression models.

Model 1 includes thecontrol variables. Although most of these coefficient estimates exhibit the expected sign (for instance, a negative coefficient for the effect of price would indicate that product concepts with a higher suggested retail price are more likely to receive a smaller fraction of votes in the product exhibition, while a positive coefficient for the effect of average NPD experience would suggest that product concepts developed by teams with more experience in NPD are more likely to receive alarger fraction of votes), they are not significantly different than zero.

Model 2 adds overall team familiarity as the key predictor variable. The coefficient estimate of overall team familiarity is not significant $(p<.218)$. This indicates that overall team familiarity does not appear to be a salient indicator of team performance in our sample. That is, teams with a higher number of past interactions were not more likely to produce a better product concept than teams with less-familiar team members. 
Model 3 includes, above and beyond the effect of overall team familiarity, the effect of average past creative interaction with a positive and significant coefficient $(5.552, p<.010)$. This result is robust to the exclusion of overall team familiarity in our model. This model suggests that, keeping team familiarity as well as all control variables constant, teams with highly positive past creative interactions, on average, are more likely to produce better product concepts. This result provides first empirical support to our hypothesis. This also confirms our conjecture that what matters is not the overall familiarity among the members of the team but the quality of such familiarity. Because it will be important to define one variable that captures the quality of team familiarity, we estimate additional regression models with alternative measures of team familiarity to test our hypothesis.

Model 4 includes, above and beyond the effect of overall team familiarity, the effect of frequent team familiarity with a negative and nonsignificant coefficient estimate. This suggests that measuring team familiarity based on past communication frequency does not yield a reliable predictor of team performance. Note that excluding overall team familiarity also yields a nonsignificant coefficient estimate of frequent team familiarity.

Model 5 includes an alternative team familiarity measure based on the notion of work-related closeness. Controlling for the effect of overall team familiarity, this model shows a positive and nonsignificant coefficient of closeness team familiarity $(6.284, p<.056)$. The coefficient of closeness team familiarity becomes positive and significant if we exclude overall team familiarity from the model (5.284, $p<.038)$. This result is consistent with our hypothesis in the sense that it is not the overall familiarity but the quality of the past relationships that predicts the likelihood of producing a creative (i.e., novel and useful) product concept.

Model 6 includes an alternative measure of team familiarity based on the notion of dyadic creative interactions (i.e., creative team familiarity). Controlling for the effect of overall team familiarity, this model shows a positive and significant coefficient estimate $(6.726, p<.015)$ of creative team familiarity, which is fully consistent with our hypothesis. This result is robust to the exclusion of overall 
team familiarity from the model: the coefficient of creative team familiarity remains positive and significant $(3.244, p<.031)$.

In addition, both models 3 and 6 exhibit the largest adjusted $R$-square of all the models estimated, which indicates that such models (which include the effects of past creative interactions) offer the best fit to the sample. Hence, teams whose members are not only familiar with each other but have also acted as creative catalysts to other team members in academic-related activities before the design exercise were more likely to produce better product concepts than teams that showed low levels of creative team familiarity.

Finally, Model 7 includes three predictor variables, which correspond to negative, neutral, and positive creative team familiarity. Note that we must exclude overall team familiarity from this model because overall team familiarity is the sum of negative, neutral, and positive creative team familiarity. The positive and significant coefficient estimate $(18.521, p<.045)$ of positive team familiarity is in line with our hypothesis. That is, teams with a higher fraction of past positive creative interactions were more likely to produce better product concepts. At the same time, Model 7's coefficient estimates of negative and neutral team familiarity are negative and positive, yet not significant, respectively.

Overall, our regression results provide empirical support to our hypothesis: teams with creative team familiarity are more likely to produce creative outcomes. We also tested for a quadratic effect of creative team familiarity and found nonsignificant quadratic effects.Figure 2 illustrates in ascatter plot the positive association between the creative team familiarity and our dependent variable(as estimated in Model 6).

Next, we describe how to use creative team familiarity to identify members of creative teams in real organizations.

\section{Example: Forming a Creative Task Force in a Real Organization}

Our results have implications for NPD organizations facing the challenge of identifying candidates to form creative teams based on creative team familiarity. The key managerial implication from our analysis is that managers of these organizations should monitor the quality of the communication patterns between 
the members of their organizations so that creative team familiarityis taken into account when forming new design teams. Two questions become relevant: 1)What aspects of thecommunication patterns within a current organizational structure should be monitored (and how)?and 2) How should such information be used to provide guidelines to managers forming new teams based on creative team familiarity? We illustrate how to address these two questions based on data collected in the new product development department of a software firm. The objective here is not to test again our working hypothesis, but rather to illustrate how to collect and use the data required to assemble potentially creative teams.

The firm studied, founded in the 1980s, is a public company that is traded on the German stock exchange. It is one of the world leaders for a particular type of application in the software industry, and its principal market consists of business customers. The firm's development organization is distributed across three locations in two neighboring European countries. During the time of data collection, the development department worked on the development of seven distinct software products [21,31].

The data was collected by surveying (almost) all the individuals in the development department, and it was used as input into a clustering algorithm we developed to identifycandidates to form design teams, based on the quality of past dyadic interactions. The survey took an average of 49 minutes to complete and was completed by 58 of the 66 people in the development department ( $88 \%$ response rate). The development department was organized formally into ten groups: seven development groups (i.e., programmers $),{ }^{5}$ one quality control group for testing all the products, one architecting and managerial group (which made important software architecture decisions and managed the department's resources), and one support group responsible for documentation and information systems. The quality/testing group was evenly distributed among the firm's three locations; the other organizational groups were almost evenly distributed between its two largest sites.

We used a combination of classic sociometric techniques ([38], pp. 43-54) to capture the technical communication patterns both within and across organizational groups associated with the development of

\footnotetext{
${ }^{5}$ One of these development groups was further divided into two small subgroups, but for the purpose of our analysis we consider it as a single functional group.
} 
the seven products in the firm's portfolio. First, each respondent was provided with a fixed roster of contacts formed by all the members of the new product development department. The full name and location of each person was clearly specified in the web-based survey, and respondents were asked to select those they had "gone to" for interactions that significantly affected their work during 2005[31].Respondents reported 633 product-related interactions in which actor $i$ "went to" actor $j$ for product-related information. This data is captured in a past interaction matrix, shown in Figure 3, in which a non-zero cell ijindicates that actor $i$ “went to" actor $j$ for technical information concerning the development of one of the products under development at the company. The sequence of this matrix is such that it also captures the formal arrangement of people into the ten organizational groups formally defined in this organization.

For each of the task-related interactionsshown in the past interaction matrix (Figure 3), we capturedthe "dyadic ease for generating potentially creative ideas" from the respondents' point of view.This was captured by asking each respondent to rate, on a seven-point Likert scale (from "strongly disagree" to "strongly agree"), their level of agreement with the following statement [31,40]: "When I interact with [name of source contact], it is easy for me to generate NOVEL creative solutions and/or ideas. These NOVEL ideas can be related either to our products or to the way we do things." Observe that here we measured the level of creativity associated with each task-related interaction in a similar fashion as we did in the initial survey of the empirical setting used to test our hypothesis described in the previous section.

Figure 4 shows a creative interaction matrix, which captures the creative interaction patterns in the organization. A non-zero $i j$ cell in this matrix indicates (on a seven-point Likert scale) the extent to which person's $i$ ease with generating potentially creative ideas after interacting with person $j$. The sequence of this matrix is identical to the one used in the matrix shown in Figure 3.

To illustrate how to use data capturing the communication patterns of an organization to form creative teams, we show howto identify, based on creative team familiarity, the candidates to formacreative task force of 11 people. We chose thisteam size arbitrarily because it isthelargest groupsize in the current formal organizational structure (the quality assurance group).Inspecting the patterns of creative 
interactions shown in Figure 4 makes it clear that identifying the candidates to form such a creative task force with maximum creative team familiarity is not a trivial task.

To address this challenge, we developed a clustering algorithm that takes the creative interaction matrix shown in Figure 4 as input[47]. Again, the objective function of this algorithm is to identify the candidates to form a given number of teams (in our example, one team of 11 actors) with maximum creative team familiarity. The solution to this hypothetical challenge is displayed in the matrix of Figure 5(a). The square matrix shown is labeled with the 11 actors who form a creative task force of 11 people with the greatest creativity team familiarity in the organization studied. The cells in this matrix show the qualitative scores of creative interaction among these actors as captured in the original creativity interaction matrix (Figure 4).

To assess qualitatively the quality of our solution, we compare it with the only 11-person group in the current organizational structure (i.e., the quality assurance group), shown in Figure 5(b). The creative task force is potentially more creative than the quality assurance group in the following aspects:

- The creative task force excludes negative creative interactions, whereas the quality assurance group has four negative past creative interactions.

- The creativity team familiarityof the creative task force is $44 \%$ greater than the creativity team familiarityof the quality assurance group.

- The creative task force balances diversity and similarityof knowledge backgrounds. Unlike the current quality assurance group, which by definition consists of actors who belong to the same group, the creative task force consists of actors who belong to fivedistinct groups. However, more than half (six of 11)of the members of the creative task force were in the same organizational group in the current organizational structure, which is consistent with previous work suggesting stirring the membership of a team with new members to increase its creative performance[15,16].

Finally, Figure 6 shows a clustered creative interaction matrix that displays the proposed creative task force as part of the rest of the organization. This allows managers to visualize not only the changes 
induced in the rest of the organization when forming the creative task force but also the links of the creative task force to the rest of the organization.Toward that end, the 11-person matrix shown in Figure 5(a) occupies the top-left corner of the clustered creative interaction matrix shown in Figure 6. Past creative interaction patterns of the proposed task force with the other groups in the organization are then highlighted on the top and left band of the clustered creative interaction matrix.

\section{Discussion}

Understanding the social drivers of creative teams is an important way to understand the human and cognitive dimensionsof engineering design[1,2]. In this paper we zoomed in on the role that team familiarity plays on the performance of creative teams in NPD settings. Although previous research has provided conflicting findings relating team familiarity and creative performance, we show that team familiarity can be an important determinant of creative teams' performance. This paper is first in recognizing thatthe quality of prior interactions among team members (before joining the team) can vary significantlyand that such variation determines the type of team familiarity that is positively associated with creative performance. Specifically, this paper argues that creative team familiarity, defined as the extent to which team members have triggered potentially creative ideas in each other in work-related tasks prior to joining the team, is an important driver of creative team performance (as opposed to overall team familiarity, which is a function of the numberof prior interactions among team members). We found empirical support for our core argument and illustrated how to use our findings to assemble creative teams in a real organization.

Identifying the members of a creative team is clearly an important yet daunting task that determines to a large extent the capability of the team to perform well[7,9]. Previous literature has suggestedassemblingcreative teams of people with the necessary expertise to carry out the task, with complementary personalities, and with strong motivation to carry out the work[9]. More recently, this literature stream has paid particular attention to the social networks of potential team members as a key ingredient to consider when forming the team $[48,49]$. Considering the social networks of potential team 
members is critical for two reasons: 1) on the external side, such networks provide the bridges to the groups outside the team that the team will have access to[49], and2) on the internal side, such networksdetermine the familiarity of the team to be formed[13].

Given our finding of a positive relationship between creative team familiarity and the ability of teams to produce innovative outcomes, we put forward a structured approach to identify potential team members that would maximize the creative team familiarity of the team to be formed.We structure such an approach in four fundamental steps, which map to Figures 3 through 6 in the previous section:

Step 1: Capturing the formal and informal organizational structure. This paper highlights the imperative for managers to not only capture the formal organizational structure (how people are formally assigned to their organizational groups) but also to document the informal organizational structure (who talks to whom for task-related matters).The objective of this step is to map out the social network within the NPD organization as illustrated by the interaction matrix shown in Figure 3.

Step 2: Measuring creative dyadic interactions. To be able to measure creative team familiarity, it is crucial to capture the quality of task-related interactions prior to forming a creative team. To do so, we suggest measuring, for each task-related interaction identified in step 1 , the extent to which the recipient of such dyads has been able to generate potentially creative ideas based on his or her interactions with the source of such a dyad. Toward that end, we suggest using a dyadic question similar to the one used in our empirical section and in the industry example discussed in section 4.1. Then, such dyadic data can be aggregatedinto a creative interaction matrix similar to the one shown in Figure 4.

Step 3: Identifying candidates for creative teams. When the need to form one (or more) new creative team(s) arises, one can use the creative interaction matrix created in step 2 as the key input to a clustering algorithm that will identify the members of the organization that should be pulled together into new team(s) with maximum creative team familiarity. This third step relies on the existence of the appropriate clustering algorithm that takes the creative interaction matrix and the needs of the NPD manager as core inputs and produces suggestions of possible creative teams with high levels of creative team familiarity as the outcome in a similar way as the 11-person task force identified in section 4.1 (see 
Figure 5(b)). Our current research efforts are focused on developing various clustering algorithms to address various types of managerial requests centered on the challenge of assembling creative teams that maximize creative team familiarity $[47,50,51]$.

Step 4: Visualizing the potential alternative organizational structure.Although our findings show that forming a creative team with high levels of creative team familiarity is likely to lead to high levels of creative performance, teams do not work in isolation. Research has also shown that the team's social network with other groups in the organization is likely to be an important driver of performance [49]. Hence, it is valuable to examine how the potential teams identified in step 3 coexist with the existing organizational groups. This can be done by resequencing the creative interaction matrix to reflect the update on the organizational structure, as illustrated in the clustered creative interaction matrix in Figure 6.This would allow the managers to visualize the number and quality of links that the potential team would have not only within the team but also with other groups in the organization.

Finding a positive link between creative team familiarity and team performance also has implications for design engineering education [52]. Although previous research has studied alternative ways to run project-based engineering design courses and alternative means to assess the performance of creative teams in such courses [53-56], we knowlittle about the levers that instructors have to improve the creative outcome (in terms of both project outcomes and learning experience) of such courses.Based on our findings, we suggest thatinstructors of such courses consider cultivating creative team familiarity as one of their key levers to improve the outcome.For instance, in a project-based course that teaches teams formed by both MBA and industrial design students how to manage the new product development process[57], we now run a one-day full-immersion team-based product design exercise (similar to the one described in section 3.4) so that teams cultivate their creative team familiarity (under the close supervision of the instructor)prior to the main long-term course project kick-off. The results from this new teaching approach have resulted in appreciably better product concepts from the course projects and 
higher levelsof student satisfaction with their learning experience from the course (as shownby a significant $10 \%$ increase in the average course rating evaluation).

As with any empirical research project, ours has limitations concerning the extent to which our findings are generalizable. We were fortunate to have access to an empirical setting that allowed us to reliably measure creative team familiarity of teams that were all going to carry out a design exercise under similar conditions. Such a setting allowed us to test whether the variation in creative outcome was positively associated with the variation observed in creative team familiarity. Although having design teams working in isolation from other teams was a necessary condition to test our hypothesis in a rigorous matter, such a condition does not allow us to say anything with respect to the effect of prior creative interactions of team members with other members with the organization outside the team boundaries. Future work in this area would benefit by studying the relative effect of creative team familiarity (as conceptualized and measured in this paper) versus the effect of external team familiarity (conceptualized as the extent to which team members have had prior creative interactions with other members of the organization).

\section{Conclusion}

Overall, this paper takes a step forward in meeting the challenge of assemblingteams tomaximize creative performance. This challenge is nontrivial and has not been fully addressed in the past - in part because of the conflicting forces driving the creativity phenomenon $[16,22,23,31,58]$. Our approach avoids forming teams based solely on traditional criteria: the diversity of the potential members' backgrounds, how well members get along, and how long team members have been working together[15,16]. Instead, we suggest considering the quality of the communication patterns of individuals in the organization as an important input to the process of assembling creative teams. Forming creative teams is an emerging topic of vital importance for successful new product development. We believe that the approach developed here has important theoretical and practical ramifications, but additional insights remain to be discovered in this nascent area of research.

\section{Acknowledgements}


For their active collaboration we thank the participants of the two classes of the TIEMBA program who participated in the empirical setup featured in this paper. We appreciate the participation of the executive team and members of the development organization discussed in the paper. We also thank Mike Danilovic for his early contributions to the initial clustering effort associated with this research. Portions of this paper and some of the data were previously presented at the ICED 2009 Conference (M. Sosa and

M. Danilovic, "A Structured Approach to Reorganize for Creativity") and the ASME DTM 2010 Conference (M. Sosa and F. Marle, “Forming Creative Teams: An Experimental Approach”).

\section{References}

[1] Cagan J., 2008, “Cognitive Based Engineering Design: An Emerging Direction of Engineering Research (Editorial)," J. Mech. Design, 130.

[2] Papalambros P., 2010, “The human Dimension (Editorial),” J. Mech. Design, 132.

[3] Dong A., Hill A., and Agonino A., 2004, "A Document Analysis Method for Characterizing Design Team Performance,” J. Mech. Design, 126(3), pp. 378-386.

[4] Olson J., Cagan J., and Kotovsky K., 2009, “Unlocking Organizational Potential: A Computational Platform for Investigating Structural Interdependence in Design,” J. Mech. Design, 131(3), 031001: 1-13.

[5] Fu K., Cagan J., and Kotovsky K., 2010, "Design Team Convergence: The Influence of Example Solution Quality,” J. Mech. Design, 132(11), 111005:1-11.

[6] Takai S., 2010, “A Game-Theoretic Model of Collaboration in Engineering Design,” J. Mech. Design, 132(5), 051005:1-10.

[7] Hackman J. R., 2002, Leading Teams: Setting the Stage for Great Performances, Harvard Business School Press, Boston, MA.

[8] Guimera R., Uzzi B., Spiro J., and Nunes Amaral L., 2005, “Team Assembly Mechanisms Determine Collaboration Network Structure and Team Performance," Science, 308, pp. 697-702.

[9] Thompson L. L., 2011, Making the Team: A Guide for Managers (4th edition), Prentice Hall.

[10] Hargadon A., and Sutton R., 1997, “Technology Brokering and Innovation in a Product Development Firm," Administrative Science Quarterly, 42, pp. 716-749.

[11] Bhavani R., and Sosa M., 2008, IDEO: Service Design (A).

[12] Reagans R., Argote L., and Brooks D., 2005, "Individual Learning Experience and Experience Working Together: Predicting Learning Rates from Knowing Who Knows What and Knowing How to Work Together," Management Science, 51(6), pp. 869-881. 
[13] Huckman R., Staats B., and Upton D., 2009, “Team Familiarity, Role Experience, and Performance: Evidence from Indian Software Services,” Management Science, 55(1), pp. 85-100.

[14] Huckman R., and Staats B., 2011, "Fluid Tasks and Fluid Teams: The Impact of Diversity in Experience and Team Familiarity on Team Performance,” Mfg. \& Serv. Oper. Mgmt, 13(3), pp. 310-328.

[15] Choi H., and Thompson L., 2005, "Old Wine in a New Bottle: Impact of Membership Change on Group Creativity,” Organizational Behavior and Human Decision Processes, 98, pp. 121-132.

[16] Skilton P., and Dooley K., 2010, "The Effects of Repeat Collaboration on Creative Abrasion," Academy of Management Review, 35(1), pp. 18-134.

[17] McCord K., and Eppinger S., 1993, "Managing the Integration Problem in Concurrent Engineering," MIT Sloan Working Paper.

[18] Morelli M. D., Eppinger S. D., and Gulati R. K., 1995, "Predicting Technical Communication in Product Development Organizations," IEEE Transaction on Engineering Management, 42(3), pp. 215-222.

[19] Sosa M. E., Eppinger S. D., and Rowles C. M., 2003, "Identifying Modular and Integrative Systems and their Impact on Design Team Interactions," J. Mech. Design, 125(2), pp. 240-252.

[20] Sosa M. E., Eppinger S. D., and Rowles C. M., 2004, "The Misalignment of Product and Organizational Structures in Complex Product Development," Management Science, 50(12), pp. 1674-1689.

[21] Sosa M. E., 2008, "A Structured Approach to Predicting and Managing Technical Interactions in Software Development," Research in Engineering Design, 19(1), pp. 47-70.

[22] Sternberg R. B., 1999, Handbook of Creativity, Cambridge University Press, Cambridge, UK.

[23] Amabile T., 1996, Creativity in Context, West View Press, Inc., Boulder, CO.

[24] Csikszentmihalyi M., 1996, Creativity, HarperCollins, New York, NY.

[25] Amabile T., 1997, "Motivating Creativity in Organizations: On Doing What You Love and Loving What You Do," California Management Review, 40(1), pp. 39-58.

[26] Simonton D. K., 1988, Scientific Genius: A Psychology of Science, Cambridge Univ. Press, Cambridge, UK.

[27] Burt R. S., 2004, “Structural Holes and Good Ideas,” American Journal of Sociology, 110, pp. 349-399.

[28] Sutton R., and Hargadon A., 1996, "Brainstorming in Groups in Context: Effectiveness in a Product Design Firm," Administrative Science Quarterly, 41, pp. 685-718.

[29] Kavadias S., and Sommer S., 2009, "The Effects of Problem Structure and Team Diversity on Brainstorming Effectiveness,” Management Science, 55(12), pp. 1899-1913.

[30] Hargadon A., and Bechky B., 2006, "When Collections of Creatives become Creative Collectives: A Field Study of Problem Solving at Work," Organization Science, 17(4), pp. 484-500.

[31] Sosa M. E., 2011, "Where do creative interactions come from? The role of tie content and social networks.," Organization Science, 22(1), pp. 1-21. 
[32] Edmonson A., 1999, "Psychological Safety and Learning Behavior in Work Teams," Administrative Science Quarterly, 44(2), pp. 350-383.

[33] McEvily B., Perrone V., and Zaheer A., 2003, "Trust as an Organizing Principle," Organization Science, 14(1), pp. 91-103.

[34] Singh V., Dong A., and Gero J., 2009, "Effects of Social Learning and Team Familiarity on Team Performance," Proceedings of the 2009 Spring Simulation Multiconference, pp. 1-8.

[35] Staats B., 2012, "Unpacking Team Familiarity: The Effects of Geographic Location and Hierarchical Role," Production and Operations Management, 21(3), pp. 619-635.

[36] Obstfeld D., 2005, "Social Networks, the Tertius Iungens Orientation, and Involvement in Innovation," Administrative Science Quarterly, 50, pp. 100-130.

[37] Edmonson A., 2012, Teaming: How Organizations Learn, Innovate, and Compete in the Knowledge Economy, John Wiley \& Sons, San Francisco, CA.

[38] Wasserman S., and Faust K., 1994, Social Networks Analysis: Methods and Applications, Cambridge University Press.

[39] Reagans R., and McEvily B., 2003, "Network Structure and Knowledge Transfer: The Effects of Cohesion and Range," Administrative Science Quarterly, 48, pp. 240-267.

[40] Tortoriello M., 2005, "The Social Underpinnings of Absorptive Capacity: External Knowledge, Social Networks, and Individual Innovativeness," CMU Working Paper.

[41] Ulrich K., and Eppinger S. D., 2012, Product Design and Development (5th ed.), McGraw-Hill.

[42] Ulrich K., 2004, “PDQ: Product Development Quick,” Teaching Note.

[43] Stein M. I., 1974, Stimulating Creativity, Academic Press, New York.

[44] Steward D. V, 1981, "The Design Structure System: A Method for Managing the Design of Complex Systems," IEEE Transaction on Engineering Management, 28(3), pp. 79-83.

[45] Eppinger S., Whitney D., Smith R., and Gebala D., 1994, “A Model-Based Method for Organizing Tasks in Product Development," Research in Engineering Design, 6, pp. 1-13.

[46] Lovejoy W., 2000, “Integrated Operations,” University of Michigan. Working Paper.

[47] Marle F., and Sosa M. E., 2010, "Forming Creative Teams Using Clustering Algorithms," Ecole Centrale Paris. Working Paper.

[48] Reagans R., Zuckerman E., and McEvily B., 2004, "How to Make the Team: Social Networks vs. Demography as Criteria for Designing Effective Teams," Administrative Science Quarterly, 49, pp. 101133.

[49] Ancona D., and Bresman H., 2007, X-Teams: How to Build Teams That Lead, Innovate, and Succeed, Harvard Business School Press, Boston, MA. 
[50] Marle F., Vidal L., and Bocquet J., 2013, "Interactions-Based Risk Clustering Methodologies and Algorithms for Complex Project Management," Intern. Journal of Production Economics, 142(2), pp. 225234.

[51] Marle F., and Vidal L.-A., 2011, "Project Risk Management Processes : Improving Coordination Using a Clustering Approach," Research in Engineering Design, 22(3), pp. 189-206.

[52] Doepker P. E., and Dym C. L., 2007, “Design Engineering Education,” J. Mech. Design, 129(7), pp. 657658.

[53] Kadlowec J., Bhatia K., Chandrupata T., Chen J., Constants E., Hartman H., Marchese A., Von Lockette P., and Zhang H., 2007, "Design Integrated in the Mechanical Engineering Curriculum: Assessment of the Engineering Clinics," J. Mech. Design, 129(7), pp. 682-691.

[54] Keefe M., Glancey J., and Cloud N., 2007, “Assessing Student Team Performance in Industry Sponsored Design Projects,” J. Mech. Design, 129(7), pp. 692-700.

[55] Hey J., Van Pelt A., Agonino A., and Beckman S., 2007, "Self-Reflection: Lessons Learned in a New Product Development Class,” J. Mech. Design, 129(7), pp. 668-676.

[56] Maier J. R., Troy T., Jud Johnston P., Bobba V., and Summers J. D., 2010, "Case Study Research Using Senior Design Projects: An Example Application,” J. Mech. Design, 132(11).

[57] Sosa M. E., 2013, "Strategies for Product and Service Development (Art Center)," course website: http://faculty.insead.edu/manuel-sosa/teaching.

[58] Linsey J. S., Tseng I., Fu K., Cagan J., Wood K. L., and Schunn C., 2010, “A Study of Design Fixation, its Mitigation and Perception in Engineering Design Faculty," J. Mech. Design, 132(4), 041003:1-12. 


\section{List of Table Captions}

Table 1: Overall characteristics of sample

Table 2: Descriptive Statistics and Pairwise Correlations $(N=20)$

Table 3: OLS coefficient estimates predicting team's product concept perceived quality $(N=20)$

\section{List of Figure Captions}

Figure 1: Key milestones in our empirical setting

Figure 2: Scatter plots of creative team familiarity and product concept design quality

Figure 3: Past interaction matrix of the firm studied

Figure 4: Creative interaction matrix of the firm studied

Figure 5: Teams of 11 actors: (a) proposed creative task force; (b) current quality assurance group

Figure 6: Clustered creative interaction matrix of the firm studied 
Table 1. Overall characteristics of sample

\begin{tabular}{ccccc} 
Graduating class & Class size & Gender ratio & Avg. age & $\begin{array}{c}\text { Avg. working } \\
\text { experience }\end{array}$ \\
\hline 2010 & 34 participants & $74 \%$ male & 38 years & 13 years \\
2011 & 50 participants & $73 \%$ male & 36 years & 12 years \\
\hline
\end{tabular}


Table 2. Descriptive Statistics and Pairwise Correlations $(N=20)$

\begin{tabular}{|c|c|c|c|c|c|c|c|c|c|c|c|c|c|c|}
\hline Variables & Mean & S.D. & 1 & 2 & 3 & 4 & 5 & 6 & 7 & 8 & 9 & 10 & 11 & 12 \\
\hline $\begin{array}{l}1 . \text { Team's } \\
\text { product } \\
\text { concept quality }\end{array}$ & 11.26 & 7.10 & 1.00 & & & & & & & & & & & \\
\hline 2. Singy & 0.60 & 0.50 & -.36 & 1.00 & & & & & & & & & & \\
\hline 3. Price & 17.26 & 39.1 & -.40 & .13 & 1.00 & & & & & & & & & \\
\hline $\begin{array}{l}\text { 4. NPD } \\
\text { experience }\end{array}$ & 0.63 & 0.23 & .25 & -.17 & -.06 & 1.00 & & & & & & & & \\
\hline $\begin{array}{l}\text { 5. Team } \\
\text { dynamics }\end{array}$ & 6.19 & 0.47 & .07 & .45 & -.21 & .18 & 1.00 & & & & & & & \\
\hline $\begin{array}{l}\text { 6. Overall } \\
\text { team } \\
\text { familiarity }\end{array}$ & 0.71 & 0.22 & .39 & -.51 & -.16 & .07 & .04 & 1.00 & & & & & & \\
\hline $\begin{array}{l}\text { 7. Avg. past } \\
\text { creative } \\
\text { interaction }\end{array}$ & 4.81 & 0.70 & .55 & -.31 & -.18 & -.13 & .02 & .12 & 1.00 & & & & & \\
\hline $\begin{array}{l}\text { 8. Frequency } \\
\text { team } \\
\text { familiarity }\end{array}$ & 0.73 & 0.27 & .23 & -.48 & -.11 & -.09 & -.04 & .84 & .21 & 1.00 & & & & \\
\hline $\begin{array}{l}\text { 9. Closeness } \\
\text { team } \\
\text { familiarity }\end{array}$ & 1.84 & 0.65 & .49 & -.51 & -.08 & -.11 & -.05 & .75 & .47 & .73 & 1.00 & & & \\
\hline $\begin{array}{l}\text { 10. Creative } \\
\text { team } \\
\text { familiarity }\end{array}$ & 3.46 & 1.21 & .57 & -.58 & -.21 & .03 & .04 & .90 & .54 & .80 & .85 & 1.00 & & \\
\hline $\begin{array}{l}\text { 11. Negative } \\
\text { creative team } \\
\text { familiarity }\end{array}$ & 0.08 & 0.11 & -.40 & .23 & .31 & .09 & -.07 & .13 & -.79 & -.07 & -.16 & -.25 & 1.00 & \\
\hline $\begin{array}{l}\text { 12. Neutral } \\
\text { creative team } \\
\text { familiarity }\end{array}$ & 0.19 & 0.13 & -.02 & -.11 & -.14 & .13 & .18 & .48 & -.48 & .50 & .15 & .19 & .23 & 1.00 \\
\hline $\begin{array}{l}\text { 13. Positive } \\
\text { creative team } \\
\text { familiarity }\end{array}$ & 0.44 & 0.22 & .59 & -.54 & -.22 & -.06 & -.03 & .63 & .79 & .55 & .72 & .88 & -.49 & -.24 \\
\hline
\end{tabular}

Note: Correlation coefficients greater than $|0.45|$ are significant at the .05 level. 
Table 3

OLS coefficient estimates predicting team's product concept perceived quality $(N=20)$

\begin{tabular}{|c|c|c|c|c|c|c|c|}
\hline Variables & Model 1 & Model 2 & Model 3 & Model 4 & Model 5 & Model 6 & Model 7 \\
\hline Singy & $\begin{array}{l}-4.984 \\
(3.710)\end{array}$ & $\begin{array}{l}-2.771 \\
(4.666)\end{array}$ & $\begin{array}{c}1.878 \\
(4.286)\end{array}$ & $\begin{array}{l}-3.212 \\
(4.828)\end{array}$ & $\begin{array}{l}-0.630 \\
(4.553)\end{array}$ & $\begin{array}{c}1.399 \\
(4.348)\end{array}$ & $\begin{array}{c}1.87 \\
(4.959)\end{array}$ \\
\hline Price & $\begin{array}{l}-0.057 \\
(0.042)\end{array}$ & $\begin{array}{l}-0.057 \\
(0.042) \\
\end{array}$ & $\begin{array}{l}-0.049 \\
(0.036) \\
\end{array}$ & $\begin{array}{l}-0.056 \\
(0.043) \\
\end{array}$ & $\begin{array}{l}-0.064 \\
(0.040)\end{array}$ & $\begin{array}{l}-0.051 \\
(0.036) \\
\end{array}$ & $\begin{array}{l}-0.042 \\
(0.041)\end{array}$ \\
\hline NPD experience & $\begin{array}{l}4.499 \\
(7.18) \\
\end{array}$ & $\begin{array}{c}5.346 \\
(7.344) \\
\end{array}$ & $\begin{array}{l}10.284 \\
(6.429) \\
\end{array}$ & $\begin{array}{c}3.989 \\
(7.836) \\
\end{array}$ & $\begin{array}{c}9.002 \\
(7.215) \\
\end{array}$ & $\begin{array}{c}8.685 \\
(6.445) \\
\end{array}$ & $\begin{array}{l}9.606 \\
(7.111) \\
\end{array}$ \\
\hline Team dynamics & $\begin{array}{c}1.994 \\
(4.007)\end{array}$ & $\begin{array}{c}0.706 \\
(4.364)\end{array}$ & $\begin{array}{l}-2.069 \\
(3.803)\end{array}$ & $\begin{array}{c}0.778 \\
(4.467)\end{array}$ & $\begin{array}{l}-0.091 \\
(4.121)\end{array}$ & $\begin{array}{l}-1.547 \\
(3.854)\end{array}$ & $\begin{array}{l}-1.648 \\
(4.338)\end{array}$ \\
\hline $\begin{array}{l}\text { Overall team } \\
\text { familiarity }\end{array}$ & & $\begin{array}{l}7.210 \\
(9.022)\end{array}$ & $\begin{array}{l}10.691 \\
(7.670)\end{array}$ & $\begin{array}{c}13.989 \\
(14.440)\end{array}$ & $\begin{array}{c}-4.682 \\
(10.965)\end{array}$ & $\begin{array}{l}-21.324 \\
(13.963)\end{array}$ & \\
\hline $\begin{array}{l}\text { Avg. past creative } \\
\text { interaction }\end{array}$ & & & $\begin{array}{l}5.552 * * \\
(2.104)\end{array}$ & & & & \\
\hline $\begin{array}{l}\text { Frequency team } \\
\text { familiarity }\end{array}$ & & & & $\begin{array}{c}-6.943 \\
(11.373)\end{array}$ & & & \\
\hline $\begin{array}{l}\text { Closeness team } \\
\text { familiarity }\end{array}$ & & & & & $\begin{array}{c}6.284 \\
(3.685) \\
\end{array}$ & & \\
\hline $\begin{array}{l}\text { Creative team } \\
\text { familiarity }\end{array}$ & & & & & & $\begin{array}{l}6.726^{*} \\
(2.740)\end{array}$ & \\
\hline $\begin{array}{l}\text { Negative creative } \\
\text { team familiarity }\end{array}$ & & & & & & & $\begin{array}{c}-9.021 \\
(16.266) \\
\end{array}$ \\
\hline $\begin{array}{l}\text { Neutral creative team } \\
\text { familiarity }\end{array}$ & & & & & & & $\begin{array}{c}5.966 \\
(13.203) \\
\end{array}$ \\
\hline $\begin{array}{l}\text { Positive creative team } \\
\text { familiarity }\end{array}$ & & & & & & & $\begin{array}{l}18.521^{*} \\
(10.006)\end{array}$ \\
\hline$R^{2}$ & .296 & .327 & .562 & .345 & .450 & .540 & .507 \\
\hline Adjusted $-R^{2}$ & .108 & .086 & .359 & .043 & .196 & .328 & .219 \\
\hline
\end{tabular}

Notes: Standard errors shown between parentheses. $* p<.05, * * p<.01$ (one-tailed) 


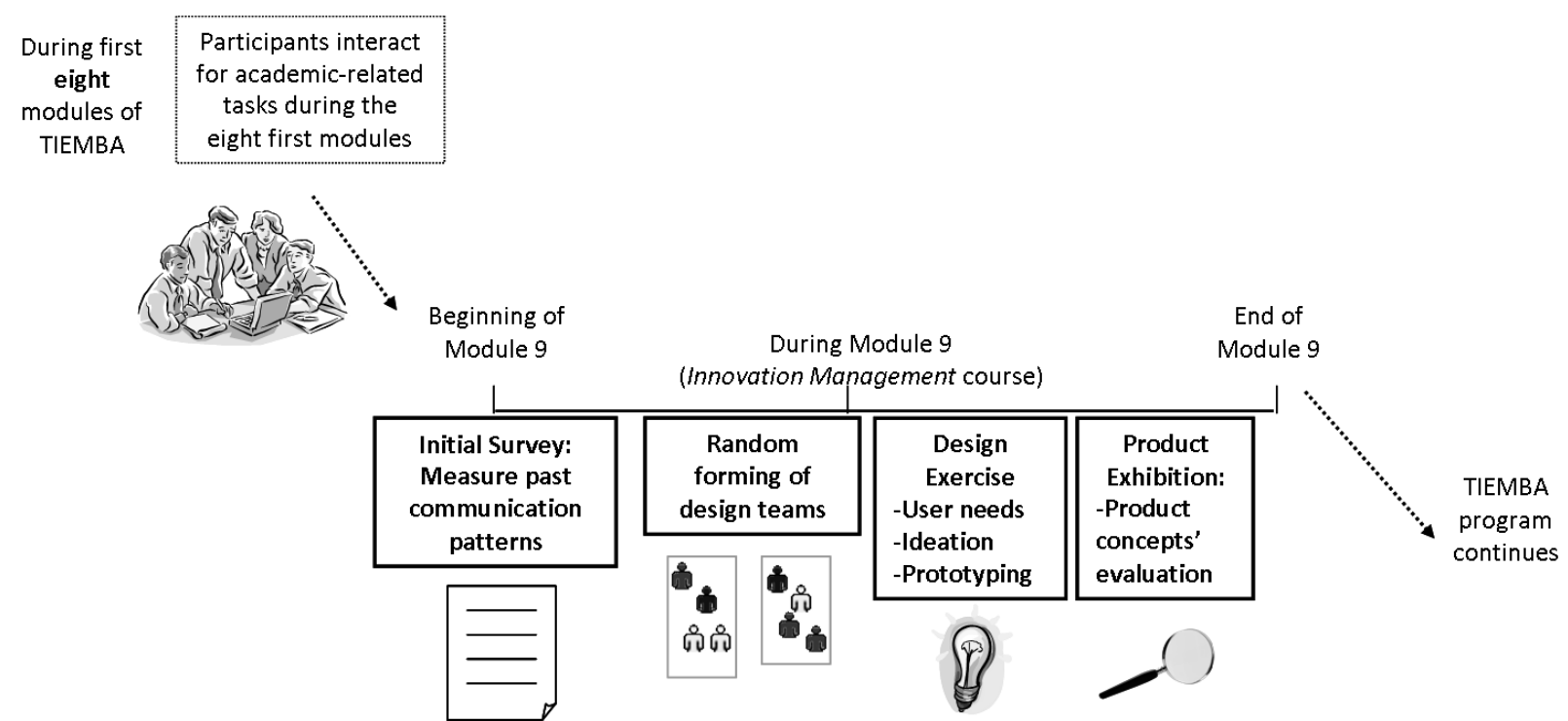

Figure 1. Key milestones in our empirical setting 


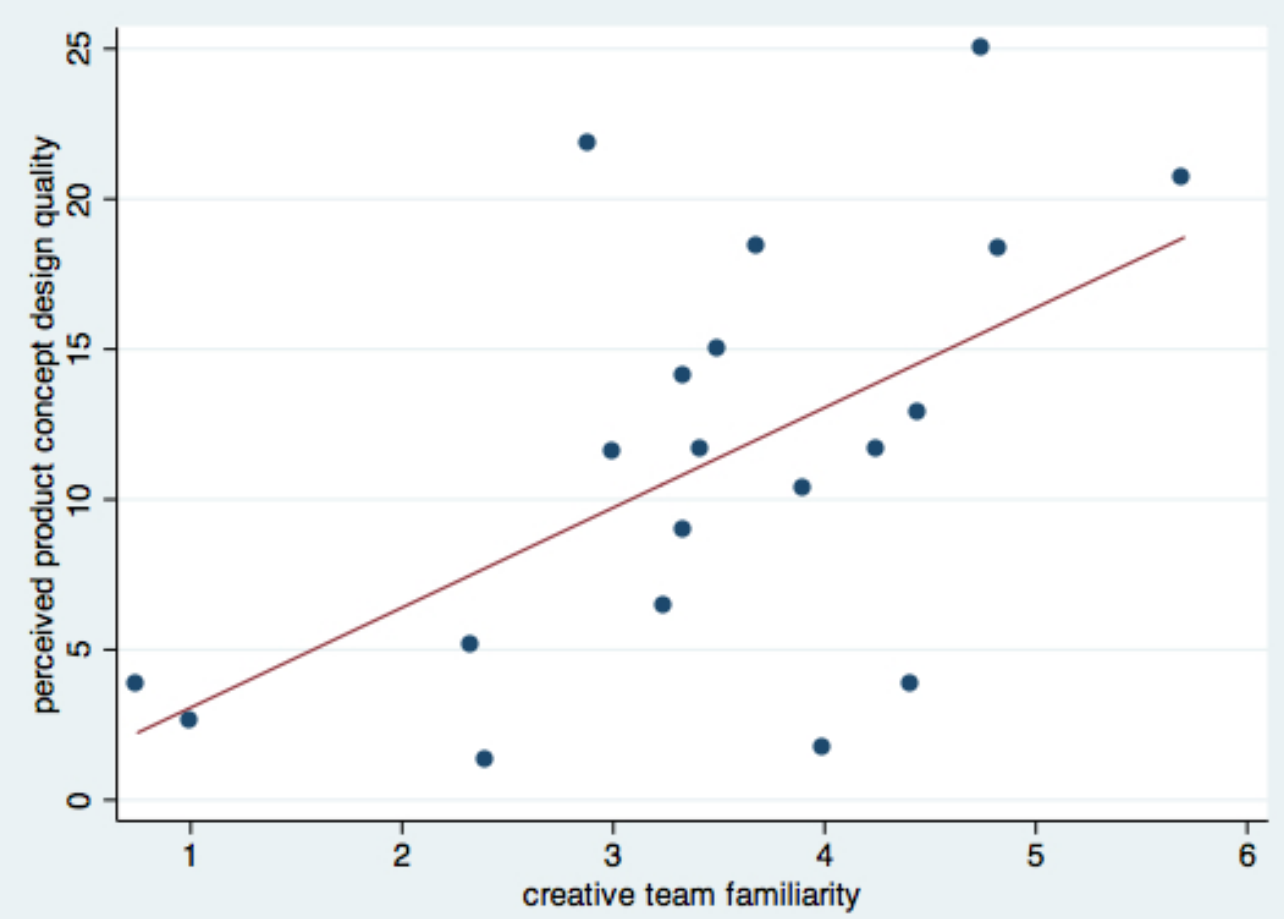

Figure 2. Scatter plots of creative team familiarity and product concept design quality 


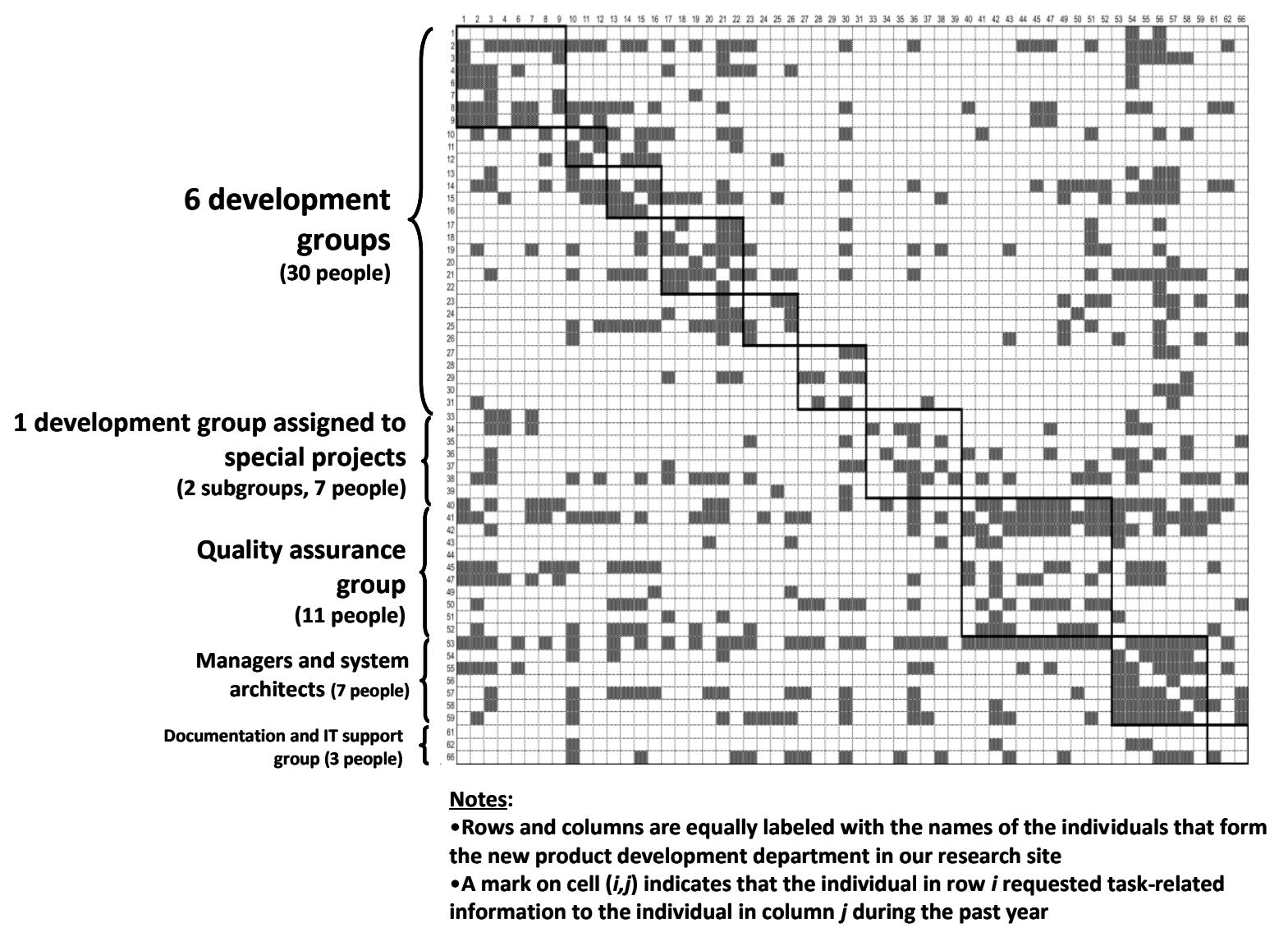

Figure 3. Past interaction matrix of the firm studied 


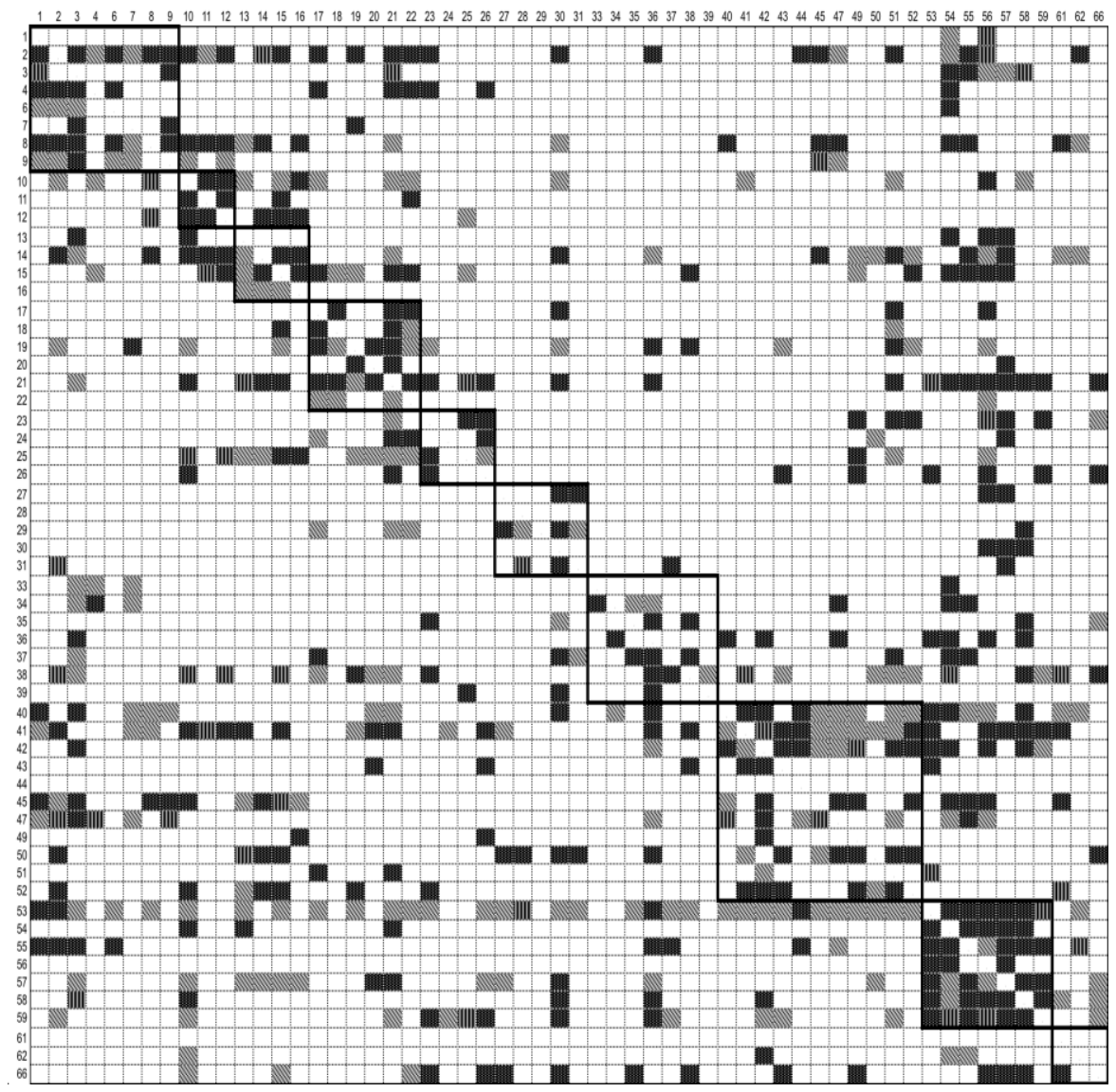

Positive creative interaction:

Actor $i$ agrees that it is easy to generate creative ideas after interacting with the actor $j$
Neutral creative interaction: Actor $i$ neither agrees nor disagrees that it is easy to generate creative ideas after interacting with the actor $j$
III Negative creative interaction: Actor $i$ disagrees that it is easy to generate creative ideas after interacting with the actor $j$

Figure 4. Creative interaction matrix of the firm studied 
(a) Proposed creative task force

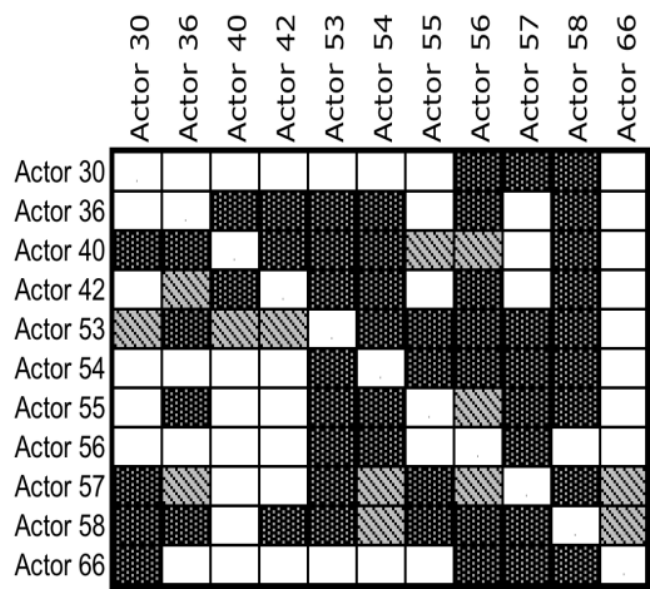

(b) Current quality assurance group

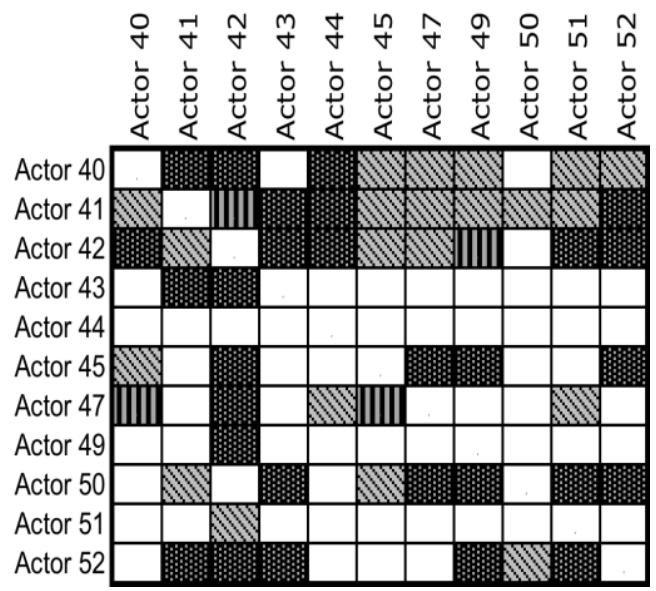

Positive creative interaction: Actor $i$ agrees that it is easy to generate creative ideas after interacting with the actor $j$
Neutral creative interaction:

Actor $i$ neither agrees nor disagrees that it is easy to generate creative ideas after interacting with the actor $j$
III Negative creative interaction: Actor $i$ disagrees that it is easy to generate creative ideas after interacting with the actor $j$

Figure 5. Teams of 11 actors: (a) proposed creative task force; (b) current quality assurance group 


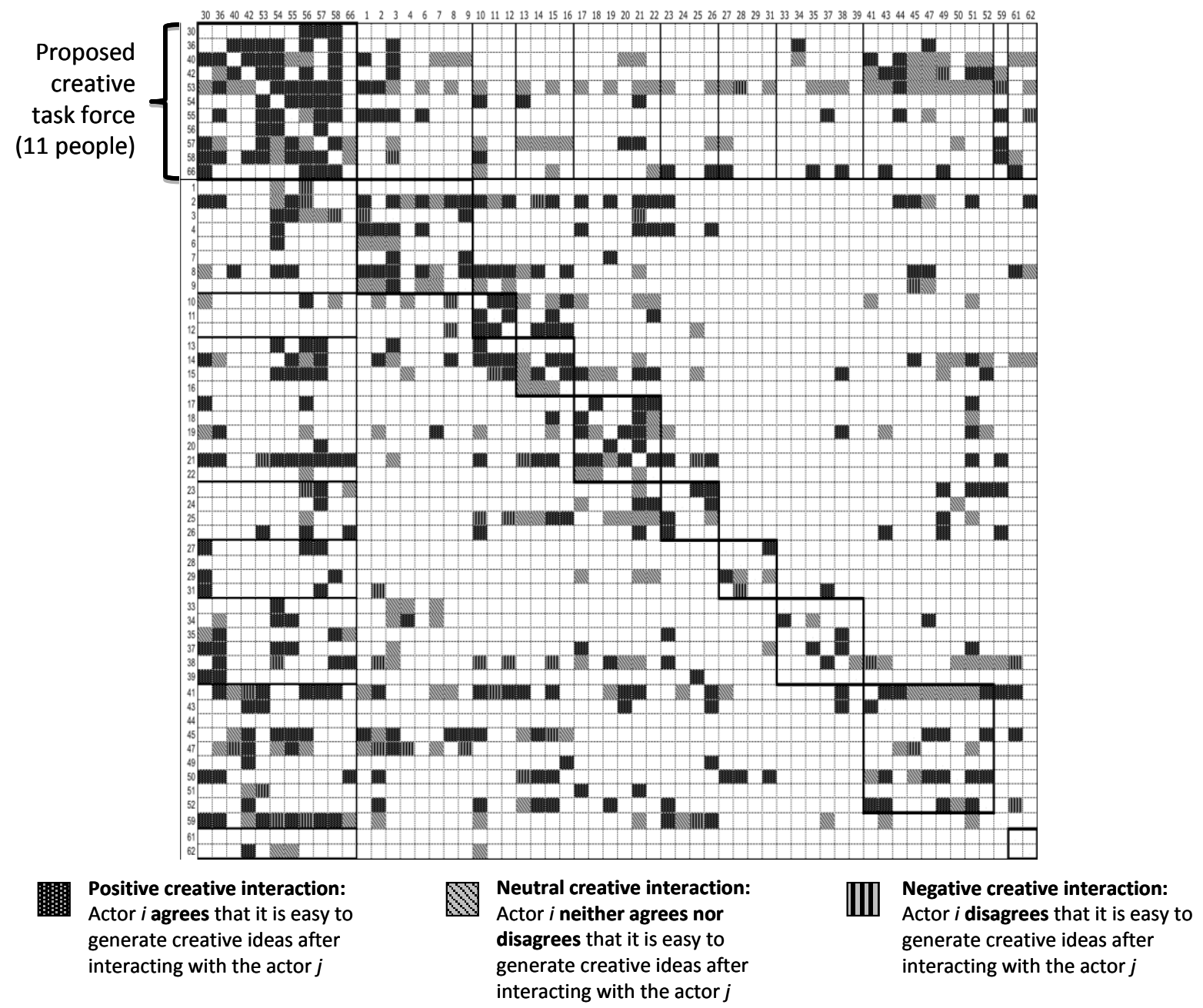

Figure 6. Clustered creative interaction matrix of the firm studied 